\title{
Speciation Analysis of Chromium in Water Samples With Pretreated Orange Peel Solid Phase Extraction and Determination by ICP-MS
}

\author{
Xianzhong Cheng ${ }^{\mathrm{a}, *}$, Yuan Peng $^{\mathrm{a}}$, Kuang Cheng ${ }^{\mathrm{b}}$, Yuyao Song ${ }^{\mathrm{a}}$, and Shunxi Zhang ${ }^{\mathrm{a}}$ \\ ${ }^{a}$ School of Chemical and Environmental Engineering, Wuhan Polytechnic University \\ Wuhan 430023, P.R. China \\ b College of Environmental Science and Engineering \\ Huazhong University of Science and Technology, Wuhan 430074, P.R. China
}

\section{INTRODUCTION}

The development of simple, selective, and accurate analytical methods for chromium speciation in environmental water samples is drawing growing attention due to different toxicological and biological properties greatly depending on its chemical form (1). Chromium is generally produced in industrial activities such as electroplating, corrosion control, leather tanning, and the production of paints and pigments. In the environment, chromium exists mainly in two oxidation states, Cr(III) and Cr(VI). Chromium(III) is known as an essential trace nutrient to normal carbohydrate, lipid, and protein metabolism and is not toxic at low concentrations, whereas Cr(VI) is generally more dangerous for humans due to its toxicity and carcinogenic properties $(2,3)$.

The permissible limit of chromium in drinking water as recommended by the Food and Agriculture Organization of the United Nations (FAO) and World Health Organization (WHO) is less than $0.05 \mathrm{mg} \mathrm{L}^{-1}$ (4). The determination of total chromium is not sufficient in evaluating the environmental impact. Therefore, the development of analytical methods for the determination of the redox species [Cr(III)/Cr(VI)] is more important than methods for total Cr. In general, the speciation analysis of chromium requires separation of

*Corresponding autbor.

E-mail: xzcheng@whpu.edu.cn

\section{ABSTRACT}

A novel method was investigated using chemically pretreated orange peel (POP) powder to separate and pre-concentrate Cr(III) in environmental water. In this study, the raw orange peel was pretreated with petroleum ether- $\mathrm{NaOH}$ and employed as selective sorbent for the separation of $\mathrm{Cr}$ (III) ions in the presence of $\mathrm{Cr}(\mathrm{VI})$. The influences of $\mathrm{pH}$, sample flow rate, elution concentration and volume, and breakthrough volume were investigated in detail. $\mathrm{Cr}$ (III) was selectively adsorbed on the microcolumn packed with POP in the $\mathrm{pH}$ range from 3.5 to 5.5 , while the unretained $\mathrm{Cr}(\mathrm{VI})$ was determined directly in the effluent. The retained $\mathrm{Cr}$ (III) was eluted with $2.0 \mathrm{~mL}$ of $1.2 \mathrm{~mol} \mathrm{~L}^{-1} \mathrm{HNO}_{3}$ followed by determination with ICP-MS.

Under the optimum conditions, the detection limits based on $3 \sigma$ criterion were $0.009 \mathrm{ng} \mathrm{mL}^{-1}$ and $0.037 \mathrm{ng} \mathrm{mL}^{-1}$ for $\mathrm{Cr}(\mathrm{III})$ and Cr(VI), respectively. The relative standard deviations (RSD) were less than $4.1 \%\left(\mathrm{n}=11, \mathrm{c}=2.0 \mathrm{ng} \mathrm{mL}^{-1}\right)$. The proposed method was successfully applied to the speciation determination of $\mathrm{Cr}$ (III) and Cr(VI) in water samples. The recoveries in spiked environmental water samples ranged from $98.5 \%$ to $103.8 \%$. A reference water sample GBW(E)080642 was also analyzed and the results were in good agreement with the certified values. the species prior to measurement using a detection system such as inductively coupled plasma mass spectrometry (ICP-MS). Often, one of the determined species is retained on the sorbent, while the other one remains in the solution.

Solid-phase extraction (SPE) has been developed for the separation and pre-concentration of analytes in environmental samples because of short extraction time, high enrichment factor, low consumption of eluent, easy automation, and the possibility of combining with different detection techniques in on-line or off-line modes (5). In an SPE procedure, the choice of appropriate adsorbent is a critical factor in obtaining high selectivity, full recovery, and a high enrichment factor. Many sorbents have been used for the separation and preconcentration of chromium species, including chelating resin $(6,7)$, ion imprinted polymer (8-10), ionic liquid (11), modified silica gel $(12,13)$, and nano materials (14-16). However, most of the above-mentioned adsorbents are expensive, require chemical synthesis, and generate secondary waste. In recent years, many natural forms of agricultural byproducts have been explored as an alternative sorbent to replace the synthetic adsorbents listed above due to their environmentally benign nature, low cost, and being easily obtained. From the review of the literature, these eco-friendly biosorbents [e.g., moss (17), eggshell membrane (18-20), animal fiber (21), cellulose (22), fungal biomass (23), and $\beta$-cyclodextrin (24), etc.] 
were widely applied in the analytical field for solid-phase extraction and determination of trace metal ions.

Orange peel (OP) is widely available as a byproduct from fruit juice production. It mainly consists of cellulose, pectin (galacturonic acid), hemi-cellulose, chlorophyll pigments and lignin, and flavonoids. There are many carboxylic, hydroxyl, and amide groups in these components, which may interact with some metallic species through electrostatic attraction, ion exchange and/or the chelation mechanism (25). In previous works, orange peel has been used as biomaterial to remove heavy metals pollutants in wastewater treatments (26-29). However, without any surface treatment, orange peel may suffer from poor selectivity and adsorption capacity. For this reason, it needs to be transformed into a waterinsoluble matrix, either by pretreatment or modification. To the best of our knowledge, pretreated orange peel as sorbent for solid phase extraction of chromium speciation has never been exploited for analytical purposes.

In the present work, a chemically pretreated orange peel (POP) was prepared in an attempt to improve its physico-chemical properties which exhibit high affinity for $\mathrm{Cr}$ (III). It can adsorb trivalent chromium very effectively, but is less effective for Cr(VI). A separation and pre-concentration system consisting of a pretreated orange peel-packed column for $\mathrm{Cr}$ (III) retention was developed and coupled to an inductively coupled plasma mass spectrometer (ICPMS). The results show that POP can be used in SPE for the efficient separation and pre-concentration of trace $\mathrm{Cr}$ (III). The proposed method has been applied for the determination of chromium species in tap water and lake water.

\section{EXPERIMENTAL}

\section{Instrumentation}

An X Series II ICP-MS system (Thermo Elemental Corporation, USA) with a concentric nebulizer was used in this work. For the elimination of matrix effects, the samples and standards were spiked with $2.0 \mathrm{ng} \mathrm{mL}^{-1}$ of ${ }^{115}$ In internal standard before measurement (30). The optimum ICP-MS operating and measurement parameters are listed in Table I.

A Nicolet AVATAR 330 Fourier transform infrared spectrometer (FT-IR) (Thermo Electron Corporation, USA) was used to identify the functional groups in the adsorbent OP and POP.

An in-house built PTFE microcolumn $(20 \mathrm{~mm} \times 2.0 \mathrm{~mm}$ i.d. $)$ was packed with modified orange peel powder in a manifold for separation/pre-concentration.

The $\mathrm{pH}$ values of the solutions were measured with a $\mathrm{pH}$ meter (Thermo Orion Corporation, USA) supplied with a combined electrode.

A certified reference material (CRM) sample, GBW(E)080642
Trace Elements in Water, was purchased from the National Research Center for CRMs, Beijing, P.R. China.

De-ionized water (DW) was used throughout this work wherever required.

The laboratory glassware was cleaned by soaking in 10\% nitric acid and rinsed with distilled water prior to use.

\section{Standard Solutions and Reagents}

The stock standard solution (1.0 $\mathrm{mg} \mathrm{mL}^{-1}$ ) of Cr(III) was purchased from the National Research Center for Certified Reference Materials, Beijing, P.R. China. Cr(VI) stock standard solution (1.0 $\mathrm{mg} \mathrm{mL}^{-1}$ ) was prepared by dissolving appropriate amounts of potassium dichromate (Shanghai Chemical Reagent Co., Ltd, Shanghai, P.R. China) in high purity water. The working standard solutions were prepared daily by appropriate dilutions of the corresponding stock solution with DW prior to their use. All reagents were of analytical grade unless otherwise stated.

TABLE I

ICP-MS Operating Conditions

$\begin{array}{ll}\text { Instrument } & \text { Thermo Elemental X Series II ICP-MS } \\ \text { Plasma power } & 1350 \mathrm{~W} \\ \text { Cool argon flow rate } & 14.0 \mathrm{~L} \mathrm{~min}^{-1} \\ \text { Auxiliary argon flow rate } & 0.78 \mathrm{~L} \mathrm{~min}^{-1} \\ \text { Nebulizer argon flow rate } & 1.00 \mathrm{~L} \mathrm{~min}^{-1} \\ \text { Sampler/Skimmer cone } & \mathrm{Ni} \\ \text { Sampling volume } & 1.0 \mathrm{~L} \mathrm{~min}{ }^{-1} \\ \text { Sampling depth } & 7.8 \mathrm{~mm}^{-} \\ \text {Sampling pattern } & \text { Quantitative } \\ \text { Scanning mode } & \text { Peak jumping } \\ \text { Measure point/peak } & 1 \\ \text { Repeated time } & 3 \\ \text { Quality resolution } & 0.65-0.80 \text { amu } \\ \text { Isotope used } & \mathrm{m} / \mathrm{z:}{ }^{52} \mathrm{Cr} \text { and }{ }^{53} \mathrm{Cr}\end{array}$




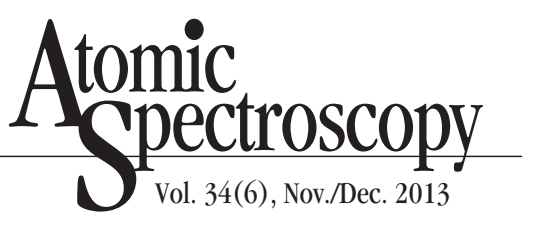

\section{Preparation of Adsorbent POP}

Orange peel (OP) was obtained from a campus fruit shop. It was washed several times with DW and dried at $70{ }^{\circ} \mathrm{C}$ for 12 hours. The dried sample was crushed and sieved to 150 mesh particle size. Then $50 \mathrm{~g}$ of dried OP was soaked in $250 \mathrm{~mL}$ petroleum ether for about 12 hours to remove chlorophyll pigments and low molecular weight polyphenols. The sample was vacuum-filtered, repeatedly washed with ethanol until there was no color in the filtrate, then dried at $70{ }^{\circ} \mathrm{C}$ for 24 hours. This sample was mixed with $250 \mathrm{~mL}$ $0.2 \mathrm{~mol} \mathrm{~L}^{-1} \mathrm{NaOH}$ and stirred for 3 hours at room temperature. The base/peel slurry was filtered, washed with distilled water until the $\mathrm{pH}$ reached neutral, and then dried at $70^{\circ} \mathrm{C}$ for 24 hours, thereafter named as POP. With this step, the number of carboxylate ligands in the biomass could be increased and the binding ability of the metal ions enhanced by treating with sodium hydroxide. The POP was stored in desiccators prior to characterization and test use.

\section{Column Preparation}

A $60 \mathrm{mg}$ quantity of the POP was packed into a PTFE microcolumn (20 $\mathrm{mm} \times 2.0 \mathrm{~mm}$ i.d.) plugged with a small portion of glass wool at both ends. Before use, $2.0 \mathrm{~mol} \mathrm{~L}^{-1}$ $\mathrm{HNO}_{3}$ and DW were passed through the column to clean and condition it. The column was then preconditioned to the desired $\mathrm{pH}$ value with $0.1 \mathrm{~mol} \mathrm{~L}^{-1} \mathrm{HNO}_{3}$ and $0.1 \mathrm{~mol} \mathrm{~L}^{-1} \mathrm{NH}_{3} \cdot \mathrm{H}_{2} \mathrm{O}$ before passing the chromium-containing solutions. The desired flow rates $(0.5-3.0 \mathrm{~mL}$ $\mathrm{min}^{-1}$ ) were easily obtained.

\section{General Procedure}

An aliquot of sample solution containing $\mathrm{Cr}$ (III) and $\mathrm{Cr}(\mathrm{VI})$ was prepared, and the $\mathrm{pH}$ value adjusted to the desired $\mathrm{pH}$ with $0.1 \mathrm{~mol} \mathrm{~L}^{-1} \mathrm{HNO}_{3}$ and $0.1 \mathrm{~mol} \mathrm{~L}^{-1}$ $\mathrm{NH}_{3} \cdot \mathrm{H}_{2} \mathrm{O}$. The sample solution was passed through the microcolumn with a peristaltic pump at a flow rate of $2.0 \mathrm{~mL} \mathrm{~min}^{-1}$. Cr(III) retained by the microcolumn was eluted with $2.0 \mathrm{~mL}$ of $1.2 \mathrm{~mol} \mathrm{~L}^{-1} \mathrm{HNO}_{3}$, followed by ICP-MS determination in the eluent, whereas Cr(VI) was found to remain in the effluent and measured directly by ICP-MS.

\section{Preparation of Real Samples and Standard Reference Material}

Tap water was collected in our laboratory after flowing for about 5 minutes, while lake water was collected locally from East Lake (Wuhan, P.R. China) and stored in polyethylene bottles. Before analysis, all of the real water samples were filtered through a $0.45 \mu \mathrm{m}$ pore size membrane to remove the suspended matter. The certified reference sample GBW (E)08642 Trace Elements in Water was diluted 5000-fold with DW before measurement. The $\mathrm{pH}$ of the samples was adjusted to the desired value with $0.1 \mathrm{~mol} \mathrm{~L}^{-1} \mathrm{HNO}_{3}$ and $0.1 \mathrm{~mol} \mathrm{~L}^{-1} \mathrm{NH}_{3} \cdot \mathrm{H}_{2} \mathrm{O}$. Then the procedure given above was applied to the samples. The blanks were prepared in the same way as the sample, but omitting the sample.

\section{RESULTS AND DISCUSSION}

\section{FTIR Analysis}

The adsorption of chromium ions onto any biomass is due to the functional groups on the components. To confirm the pretreatment of the biomass, FTIR spectra were obtained on the raw and pretreated biomass. The IR spectra of the POP and $O P$ were recorded in the range of 4000-400 cm , and are shown in Figure 1. The FTIR spectrum of POP exhibits a broad peak at $3416 \mathrm{~cm}^{-1}$, which corresponds to the $\mathrm{O}-\mathrm{H}$ stretching vibrations of cellulose, pectin, absorbed water, hemicelluloses, and lignin (32). The peak at $2924 \mathrm{~cm}^{-1}$ could be assigned to the $-\mathrm{CH}_{2}-$ group in the cellulose (33). The peak observed at $1609 \mathrm{~cm}^{-1}$ may be assigned to the carbonyl $(-\mathrm{C}=\mathrm{O})$ stretching from the carboxylic acid and carboxylate groups, respectively. The bands observed in 1000-1300 $\mathrm{cm}^{-1}$ were assigned to the $\mathrm{C}-\mathrm{O}$ stretching vibration of the carboxylic acids and alcohols. These results were similar to the FT-IR results by Feng et al. (29).

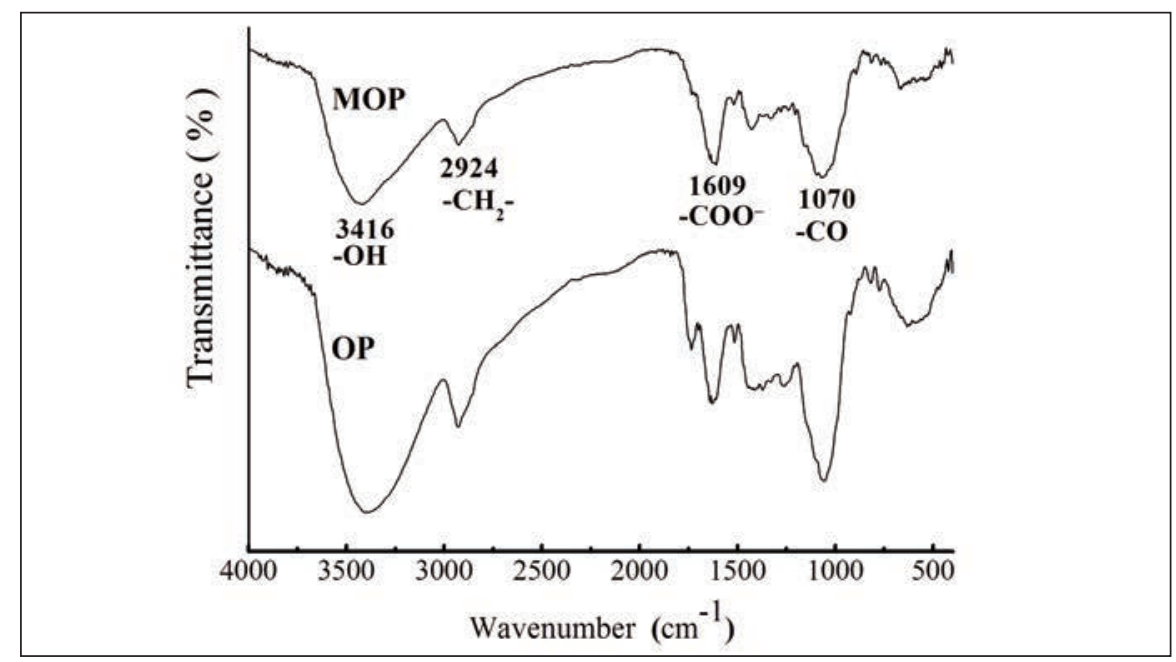

Fig. 1. FTIR spectra of $O P$ and Pretreated $O P$. 


\section{Effect of $\mathbf{p H}$ on Adsorption of Cr(III) and Cr VI)}

The solution $\mathrm{pH}$ has been suggested as one of the most important parameters with respect to the selective retention of $\mathrm{Cr}$ (III) over Cr(VI) on the POP microcolumn. In this work, the effect of $\mathrm{pH}$ on the adsorption rate of chromium species in the microcolumn was evaluated with the solution containing $5 \mathrm{ng} \mathrm{mL}^{-1}$ of $\mathrm{Cr}(\mathrm{III})$ and $\mathrm{Cr}(\mathrm{VI})$ at the $\mathrm{pH}$ varying from 2.0 to 8.0 ,

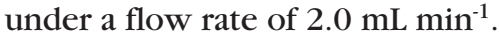
Figure 2 shows that the quantitative recovery (>96\%) for Cr(III) was obtained in the $\mathrm{pH}$ range of 3.5-5.0, whereas Cr(VI) was less than $2.0 \%$. It can be seen that the Cr(III) adsorption was favorable at $\mathrm{pH}$ 4. The adsorption behavior of $\mathrm{Cr}(\mathrm{III})$ and $\mathrm{Cr}(\mathrm{VI})$ on POP may be attributed to this reason. At $\mathrm{pH}>3$, the number of negatively charged absorbent sites increased, which provides a favorable force of attraction for the positively charged $\mathrm{Cr}$ (III) cations $\left[\mathrm{Cr}^{3+}, \mathrm{Cr}(\mathrm{OH})^{2+}\right.$, and $\left.\mathrm{Cr}(\mathrm{OH})^{2+}\right]$ (34). However, the negatively charged $\mathrm{Cr}(\mathrm{VI})$ species $\left[\mathrm{Cr}_{2} \mathrm{O}_{7}{ }^{2-}, \mathrm{HCrO}_{4}^{-}\right.$, and $\left.\mathrm{CrO}_{4}{ }^{2-}\right]$ may hardly be adsorbed due to electrostatic repulsion. At $\mathrm{pH}<2.0$, because the surface active sites of the POP were protonated, the competition of $\mathrm{H}^{+}$with the $\mathrm{Cr}$ (III) cations for the same surface sites resulted in a decrease in the adsorption of $\mathrm{Cr}$ (III). This mechanism is in agreement with the findings of previous reports on other biosorbents (35). Various mechanisms such as electrostatic repulsion and attraction, ion exchange, and chelation could be attributed to causing adsorption of $\mathrm{Cr}$ (III) on biosorbent surfaces. In the experiment, $\mathrm{pH} 4.0$ proved to be best suited for Cr(III) separation by POP.

\section{Influence of Sample Flow Rate}

The flow rate of the sample solution is a very important factor affecting the pre-concentration efficiency of $\mathrm{Cr}$ (III), recovery rate, and analysis time. The flow rate (0.5-3.0 $\left.\mathrm{mL} \mathrm{min}^{-1}\right)$ of the sample solution containing $1.0 \mathrm{ng} \mathrm{mL}^{-1}$ Cr(III) was examined at $\mathrm{pH} 4$. It can be seen from Figure 3 that the recovery rates were higher than 95\% for a sample solution flow rate of $0.5-2.5 \mathrm{~mL} \mathrm{~min}^{-1}$. Above $2.5 \mathrm{~mL}$ $\min ^{-1}$, the recovery rates decreased with an increase in flow rate of the sample solution. Therefore, a flow rate of $2.0 \mathrm{~mL} \mathrm{~min}^{-1}$ was applied for the sample solutions in all experiments.

\section{Elution of Cr(III)}

The choice of a suitable eluent is also important for pre-concentration and separation. From Figure 2 it can be seen that the adsorption of $\mathrm{Cr}$ (III) on POP is negligible at $\mathrm{pH} 1$. In acidic conditions, due to the protonation of all functional groups such as $-\mathrm{COOH},-\mathrm{OH}$, $-\mathrm{NH}_{2}$, etc., in the POP biosorbent and the competition of the $\mathrm{H}^{+}$ion with Cr(III) cations for the effective adsorption sites on the sorbent, desorption of the Cr(III) species from the POP surface is possible. For this reason, various concentrations and volumes of $\mathrm{HNO}_{3}$ were explored for the elution of Cr(III) retained in the microcolumn at

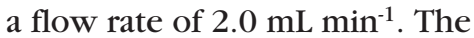
desorption efficiency of $\mathrm{Cr}$ (III) with 0.1-1.6 mol L-1 $\mathrm{HNO}_{3}$ solution and 0.5-3.0 mL $\mathrm{HNO}_{3}$ was investigated. The results indicated that quantitative recoveries for $\mathrm{Cr}$ (III) could be obtained with $2.0 \mathrm{~mL}$ of $1.2 \mathrm{~mol} \mathrm{~L}^{-1}$ $\mathrm{HNO}_{3}$. Thus, the optimum volume of $\mathrm{HNO}_{3}\left(1.2 \mathrm{~mol} \mathrm{~L}^{-1}\right)$ solution chosen for this work was $2.0 \mathrm{~mL}$ with a recovery of $>96 \%$.

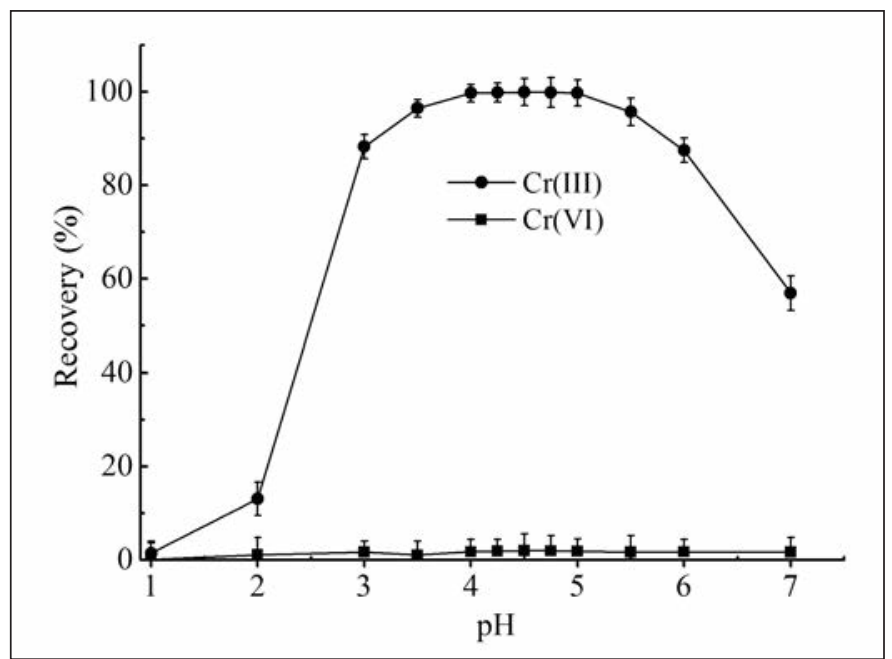

Fig. 2. Effect of pH on adsorption of Cr(III) and Cr(VI)

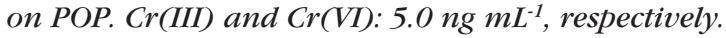
Sample volume: $20 \mathrm{~mL}$

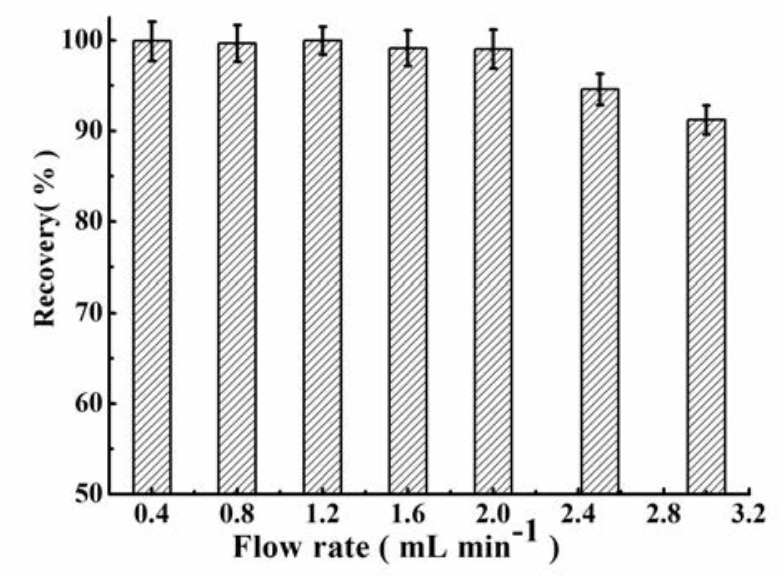

Fig. 3. Effect of flow rate of sample solution on recovery of

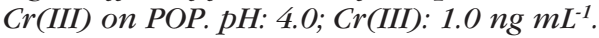




\section{Effect of Sample Volume}

The influences of sample volume on the recovery of $\mathrm{Cr}$ (III) were studied. Sample volume is a main parameter for obtaining a high preconcentration factor. For this purpose, $10 \mathrm{ng}$ of $\mathrm{Cr}$ (III) was dissolved in different DW volumes ranging from 25-250 $\mathrm{mL}$ and the recommended procedure according to optimized experimental conditions was followed. Figure 4 shows that quantitative recoveries of $\mathrm{Cr}$ (III) (>96\%) were found to be stable up to $200 \mathrm{~mL}$. Above $200 \mathrm{~mL}$, the recoveries decreased slightly with an increase in sample volume. In this study, the pre-concentration factor was calculated by the ratio of highest sample volume $(200 \mathrm{~mL})$ and final elution volume $(2 \mathrm{~mL})$. Thus, the pre-concentration factor was 100 -fold in this method.

\section{Adsorption Capacity}

The adsorption capacity study as recommended by Kalyan et al. (35) was adopted under the optimized conditions. Accordingly, $20 \mathrm{~mL}$ of sample solutions of a series of concentrations (5.0-300 $\mu \mathrm{g} \mathrm{mL}^{-1}$ ) were adjusted to the appropriate $\mathrm{pH}$, and the proposed procedure was followed. The breakthrough curve was determined by plotting the concentration $\left(\mu \mathrm{g} \mathrm{mL}^{-1}\right)$ versus the milligram of $\mathrm{Cr}(\mathrm{III})$ adsorbed on per gram of POP. The adsorption capacity calculated from the breakthrough curve was $136.2 \mathrm{mg} \mathrm{g}^{-1}$ at $\mathrm{pH} 4.0$.

\section{Effect of Ratio of Cr(III) to Cr(VI)}

In aqueous solution, the change in the redox equilibrium state may occur between $\mathrm{Cr}$ (III) and $\mathrm{Cr}(\mathrm{VI})$, and thus the concentration of the

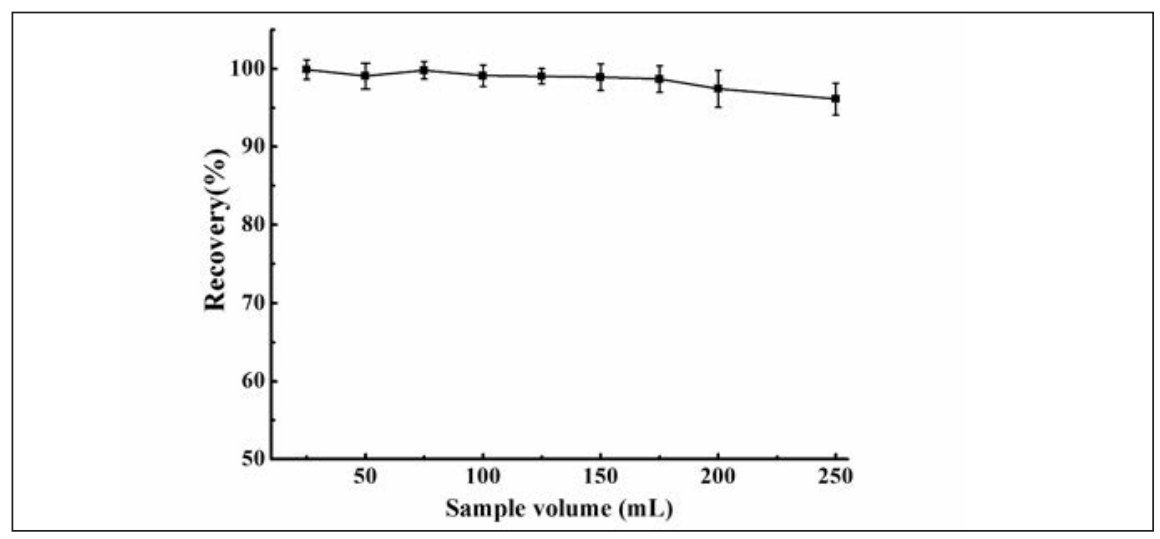

Fig. 4. Effect of sample volume on recovery of $\mathrm{Cr}$ (III) on POP. pH: 4.O; Cr(III): $10 \mathrm{ng}$

TABLE II

Recovery of Chromium Speciation in Different Concentration Ratios of $\mathrm{Cr}$ (III) and $\mathrm{Cr}(\mathrm{VI})(\mathrm{n}=3)$

\begin{tabular}{cccccc}
\hline $\begin{array}{l}\text { Cr(III)/ } \\
\text { Cr(VI) } \\
\text { Ratio }\end{array}$ & $\begin{array}{c}\text { Added } \\
\left(\mu \mathrm{g} \mathrm{L}^{-1}\right)\end{array}$ & $\begin{array}{c}\text { Found } \\
\left(\mu \mathrm{g} \mathrm{L}^{-1}\right)\end{array}$ & $\begin{array}{c}\text { Recovery } \\
(\%)\end{array}$ & $\begin{array}{c}\text { Found } \\
\left(\mu \mathrm{g} \mathrm{L}^{-1}\right)\end{array}$ & $\begin{array}{c}\text { Recovery } \\
(\%)\end{array}$ \\
\hline 0.5 & 5 & $4.93 \pm 0.11$ & 98.6 & $9.87 \pm 0.08$ & 98.7 \\
1 & 5 & $5.00 \pm 0.09$ & 100 & $4.97 \pm 0.12$ & 99.4 \\
5 & 20 & $19.9 \pm 0.21$ & 99.5 & $3.96 \pm 0.04$ & 99.0 \\
10 & 20 & $19.7 \pm 0.14$ & 98.5 & $2.04 \pm 0.05$ & 102 \\
\hline
\end{tabular}

\section{Atomic Spectroscopy $\bigcirc$ Vol. 34(6), Nov./Dec. 2013}

chromium species may change. To study the recovery and selectivity in standard solutions, the effect of the ratio of $\mathrm{Cr}$ (III) to $\mathrm{Cr}(\mathrm{VI})$ on the analytical results was evaluated. The results presented in Table II show that quantitative recoveries of $\mathrm{Cr}$ (III) and $\mathrm{Cr}(\mathrm{VI})$ were obtained with the ratio of $\mathrm{Cr}(\mathrm{III}) / \mathrm{Cr}(\mathrm{VI})$ ranging from 0.5 to 10 , and that the two species of chromium are completely separated and relatively stable at $\mathrm{pH} 4$.

\section{Interferences of Coexisting Ions}

The separation procedure was applied to the determination of $\mathrm{Cr}$ (III) and Cr(VI) species in different concentrations of coexisting ions. The representative potential interference ions were added individually to a 50-mL aqueous solution containing $1.0 \mathrm{ng} \mathrm{mL}-1$ of $\mathrm{Cr}(\mathrm{III})$ and $\mathrm{Cr}(\mathrm{VI})$, respectively. The potential interferences from coexisting ions on the separation and determination of chromium speciation were investigated. In these experiments, the tolerance limit of coexisting ions is defined as the ion concentration causing a relative error of less than $\pm 5 \%$ for $1.0 \mathrm{ng} \mathrm{mL}^{-1} \mathrm{Cr}$ (III) and $\mathrm{Cr}(\mathrm{VI})$, respectively. The results in Table III show that the recoveries of $\mathrm{Cr}$ (III) and $\mathrm{Cr}(\mathrm{VI})$ were almost quantitative in the presence of all coexisting ions and that most of the probable coexisting cations and anions did not interfere. The tolerable levels of some heavy metal ions were suitable for the separation of the Cr(III) species in the water samples examined because the levels of the transition metals in these samples were lower than their interference level.

\section{Column Re-use}

To investigate the re-usability and potential regeneration of the adsorbent, several adsorption/ desorption operation cycles were carried out in this work. The column could be re-used after regeneration with $10 \mathrm{~mL}$ of $1.2 \mathrm{~mol} \mathrm{~L}^{-1}$ 
$\mathrm{HNO}_{3}$ solution and $50 \mathrm{~mL}$ of DW, and is stable up to 20 adsorptionelution cycles without any noticeable decrease in the recovery of Cr(III).

\section{Analytical Performance of the Method}

The calibration curve for $\mathrm{Cr}$ (III) was linear up to $100 \mathrm{ng} \mathrm{mL}^{-1}$ with a correlation coefficient $\left(r^{2}\right)$ of 0.9993. According to the definition of IUPAC $(3 \sigma)$, the detection limit of this method was $0.009 \mathrm{ng} \mathrm{mL}^{-1}$ for $\mathrm{Cr}$ (III) and $0.037 \mathrm{ng} \mathrm{mL}^{-1}$ for Cr(VI) using ICP-MS determination. The relative standard deviations (RSDs), examined by 11 replicate measurements of $2.0 \mathrm{ng} \mathrm{mL}^{-1} \mathrm{Cr}$ (III) and $\mathrm{Cr}(\mathrm{VI})$ model solutions, were $2.5 \%$ for $\mathrm{Cr}(\mathrm{III})$ and $4.1 \%$ for $\mathrm{Cr}(\mathrm{VI})$, respectively. The pre-concentration factor was 100 .

A comparison of the proposed method with others in the literature is given in Table IV. As can be seen, the present method using the POP system has a high pre-concentration factor $(11,20,21,24,36)$, and the detection limit is better than other methods described in the literature $(11,21,24)$. Pretreated orange peel is a green sorbent of low cost, requiring only simple preparation in comparison to different sorbents.

\section{Application of Method to Real Samples}

The accuracy of the proposed method was validated by the determination of total chromium and its species using a standard reference materials of GBW (E)080642 Trace Elements in Water after 5000-fold dilution with DW. The analytical results were in good agreement with the reported total $\mathrm{Cr}$ concentration of $100 \pm 5 \mu \mathrm{g} \mathrm{mL}^{-1}$ (Table V).

By analyzing two real water samples (tap and lake water), followed by the spike addition of standards, the feasibility of determining Cr(III) and $\mathrm{Cr}(\mathrm{VI})$ on POP was confirmed. In addition, the recovery experi- ments of different amounts of $\mathrm{Cr}$ (III) and Cr(VI) were carried out using the standard addition method to assess the selectivity and precision. The results in Table $\mathrm{V}$ show that good agreement was obtained between the added and measured analysis amounts. These results indicate that the $\mathrm{Cr}$ (III) and $\mathrm{Cr}$ (VI) species were completely separated and quantitatively recovered, ranging from $98.5-103.8 \%$. Thus, the method was successfully applied for the separation and speciation of chromium using POP sorbent and the determination of trace $\mathrm{Cr}$ (III) and $\mathrm{Cr}(\mathrm{VI})$ in environmental water samples.

TABLE III

Influence of Coexisting Ions on Determination Cr(III) and $\mathrm{Cr}$ (VI)

\begin{tabular}{cccccccc}
\hline Ions & $\begin{array}{c}\text { Amount } \\
(\mu \mathrm{g})\end{array}$ & \multicolumn{2}{c}{ Recovery (\%) } & Ions & \multicolumn{2}{c}{$\begin{array}{c}\text { Amount } \\
(\mu \mathrm{III})\end{array}$} & \multicolumn{2}{c}{$\mathrm{Cr}(\mathrm{VI})$} & & $\mathrm{Cr}(\mathrm{III})$ & $\mathrm{Cr}(\mathrm{VI})$ \\
\hline $\mathrm{K}^{+}$ & 2500 & 101.2 & 98.6 & $\mathrm{Cu}^{2+}$ & 25 & 96.9 & 95.5 \\
& 5000 & 95.2 & 94.6 & & 50 & 95.7 & 95.1 \\
$\mathrm{Na}^{+}$ & 2000 & 99.5 & 101.3 & $\mathrm{Zn}^{2+}$ & 50 & 97.3 & 98.2 \\
& 3000 & 98.7 & 96.2 & & 100 & 97.0 & 96.1 \\
$\mathrm{Ca}^{2+}$ & 1000 & 102.4 & 97.8 & $\mathrm{Cd}^{2+}$ & 50 & 99.4 & 96.9 \\
& 2500 & 96.5 & 95.2 & & 100 & 101.2 & 97.3 \\
$\mathrm{Mg}^{2+}$ & 1000 & 97.2 & 98.9 & $\left.\mathrm{~V}^{2+}\right)$ & 25 & 100.5 & 98.6 \\
& 2500 & 95.8 & 96.7 & & 50 & 95.1 & 96.4 \\
$\mathrm{Al}^{3+}$ & 100 & 96.9 & 95.8 & $\mathrm{SO}_{4}^{2-}$ & 1000 & 98.2 & 98.9 \\
& 200 & 95.2 & 95.3 & & 1500 & 96.5 & 95.7 \\
$\mathrm{Fe}^{3+}$ & 100 & 98.1 & 98.6 & $\mathrm{PO}_{4}^{3-}$ & 1000 & 95.7 & 97.2 \\
& 150 & 96.4 & 95.9 & & 1500 & 94.1 & 93.6 \\
\hline
\end{tabular}

TABLE IV

Comparison of Present Method With Other SPE Methods

\begin{tabular}{|c|c|c|c|c|c|}
\hline Adsorbent & Method & Medium & $\mathrm{PF}^{\mathrm{a}}$ & $\begin{array}{c}\mathrm{DL}^{\mathrm{b}} \\
\left(\mu \mathrm{g} \mathrm{L}^{-1}\right)\end{array}$ & Reference \\
\hline Ion-imprinted polymer & ETAAS & $\mathrm{pH} 3.5-4.75$ & 10 & 0.018 & (11) \\
\hline Eggshell membrane & ETAAS & pH 2.0 & 13.3 & 0.01 & $(20)$ \\
\hline Animal fiber & FAAS & $\mathrm{pH} 4.0$ & 32 & 0.3 & (21) \\
\hline B-cyclodextrin & GFAAS & $\mathrm{pH}$ 5.5-6.0 & 25 & 0.056 & $(24)$ \\
\hline Carbon nanotubes & ICP-MS & $\mathrm{pH} 2.0-4.0$ & 63 & 0.01 & (36) \\
\hline $\begin{array}{l}\text { Pretreated orange } \\
\text { peel }\end{array}$ & ICP-MS & $\mathrm{pH} 3.0-5.5$ & 100 & 0.009 & $\begin{array}{l}\text { This } \\
\text { work }\end{array}$ \\
\hline
\end{tabular}

${ }^{\mathrm{a}} \mathrm{PF}=$ preconcentration factor. $\quad{ }^{\mathrm{b}} \mathrm{DL}:=$ detection limit. 


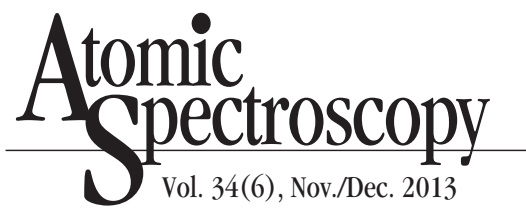

TABLE V

Analytical Results for Chromium Speciation in SRM and Water Samples $(n=3)$

\begin{tabular}{|c|c|c|c|c|c|c|c|}
\hline \multirow[t]{2}{*}{ Sample } & \multicolumn{2}{|c|}{ Spiked $\left(\mathrm{ng} \mathrm{mL}^{-1}\right)$} & \multicolumn{3}{|c|}{ Found (ng $\mathrm{mL}^{-1}$ ) } & \multicolumn{2}{|c|}{ Recovery(\%) } \\
\hline & Cr (III) & $\mathrm{Cr}(\mathrm{VI})$ & $\mathrm{Cr}$ (III) & $\mathrm{Cr}(\mathrm{VI})^{\mathrm{b}}$ & Total Cr & $\mathrm{Cr}(\mathrm{III})$ & $\mathrm{Cr}(\mathrm{VI})$ \\
\hline GBW(E)080642a & 0 & 0 & $24.82 \pm 0.9$ & $75.56 \pm 1.3$ & $100.38 \pm 2.0$ & & \\
\hline \multirow[t]{3}{*}{ Tap Water } & 0 & 0 & $0.63 \pm 0.02$ & $<\mathrm{LOD}$ & $0.62 \pm 0.03$ & & \\
\hline & 2.0 & 2.0 & $2.65 \pm 0.08$ & $2.01 \pm 0.04$ & $4.62 \pm 0.12$ & 101.0 & 100.5 \\
\hline & 5.0 & 5.0 & $5.61 \pm 0.14$ & $4.94 \pm 0.19$ & $12.79 \pm 0.32$ & 99.6 & 98.8 \\
\hline \multirow[t]{3}{*}{ Lake Water } & 0 & 0 & $4.26 \pm 0.11$ & $1.38 \pm 0.05$ & $6.64 \pm 0.34$ & & \\
\hline & 2.0 & 2.0 & $6.23 \pm 0.22$ & $3.43 \pm 0.08$ & $10.64 \pm 0.31$ & 98.5 & 102.5 \\
\hline & 5.0 & 5.0 & $9.45 \pm 0.28$ & $6.35 \pm 0.17$ & $16.58 \pm 0.34$ & 103.8 & 99.4 \\
\hline
\end{tabular}

\footnotetext{
${ }^{a}$ The GBW(E)080642 sample was detected after 5,000-fold dilution.
}

${ }^{\mathrm{b}}$ Certified value of total Cr in GBW(E)080642: $100 \pm 5 \mu \mathrm{g} \mathrm{mL}{ }^{-1}$.

\section{CONCLUSION}

In this work, a new and inexpensive method is applied for the speciation of chromium by solid phase extraction (SPE) combined with inductively coupled plasma mass spectrometry (ICP-MS). Cr(III) was selectively retained on the pretreated orange peel (POP) microcolumn in the $\mathrm{pH}$ ranging from 3.5 to 5.5 , while Cr(VI) was retained in the solution. The results showed that POP possesses good potential for the separation and determination of $\mathrm{Cr}$ (III) and $\mathrm{Cr}$ (VI) in natural water samples. The proposed method is characterized as simple, selective, and low cost, as well as safe, effective, more rapid, and cleaner. It provides good sensitivity, selectivity, and detection limits, as well as a high pre-concentration factor, and is potentially useful in the speciation analysis of $\mathrm{Cr}$ (III) and Cr(VI). It was successfully applied to the separation and determination of chromium species in environmental water samples with satisfactory results.

\section{ACKNOWLEDGMENTS}

This work was supported by the Hubei Provincial Natural Science Foundation of P.R. China (No. 2008CDA100, 2009CDA11).

$\overline{\text { Received August 17, } 2013 .}$

\section{REFERENCES}

1. T.G. Kazi, H.I. Afridi, N. Kazi, M.K. Jamali, M.B. Arain, and N. Jalbanil, Bio. Trace Elem. Res. 122, 1 (2008).

2. A.M. Zayed, and N. Terry, Plant. Soil. 249, 139 (2003).

3. R. Dobrowolsk, and M. Otto, Adsorption 16, 279 (2010).

4. G.F. Nordberg, B.A. Fowler, M. Nordberg, and L. Friberg, Handbook on the Toxicology of Metals, Academic Press, Burlington, VT, USA (2007).

5. K. Pyrzynska, TrAC Trends Anal. Chem. 32, 100 (2012).

6. M.M.L. Guerrero, E.V. Alonso, J.M.C. Pavón, M.T.S. Cordero, and A.G. Torres, J. Anal. At. Spectrom. 27, 682 (2012).

7. Ş. Saçmacı, Ş. Kartal, Y. Yılmaz, M. Saçmac1, and C. Soykan, Chem. Eng. J. 181, 746 (2012).

8. L. Zhang, Z. Li, X. Du, R. Li, and X. J. Chang, Spectrochim. Acta, Part A, 86, 443 (2012).

9. J. Liu, X.L Yang, X.Z. Cheng, Y. Peng and H.M. Chen, Anal. Methods 5, 1811 (2013).

10. B. Leśniewska, B. GodlewskaŻyłkiewicz, and A.Z. Wilczewska, Microchem. J. 105, 88 (2012).

11. C. Sarbajna, S. Durani, and S. Nayak, At. Spectrosc. 34, 31 (2013).

12. M. Imamoglu and V. Gunes, At. Spectrosc. 33, 205 (2012).
13. Y. Li, G. Hou, and B. Zhou; At. Spectrosc. 33, 130 (2012).

14. X. Liu, J.J. Xiang, Y. Tang, X.L. Zhang, Q.Q. Fu, J.H. Zou, and Y.H. Lin, Anal. Chim. Acta 745, 99 (2012).

15. S. Chen, Y. He, D. Lu, and X. Guo, At. Spectrosc. 34, 73 (2013).

16. I. Durukan, M. Soylak, and M. Dogan, At. Spectrosc. 34, 20 (2013).

17. M.V. Balarama Krishna, K. Chandrasekaran, S.V. Rao, D. Karunasagar, and J. Arunachalam, Talanta 65, 135 (2005).

18. X.Z. Cheng, J. Liu, X. Yang, H. Chen, and Y. Wang, At. Spectrosc 32, 175 (2011).

19. X.Z. Cheng, K. Shao, S. Shen, S.H. $\mathrm{Hu}$, and H.O. Qiu, Geostand. Geoanal. Res. 35, 461 (2011).

20. A.M. Zou, X.W. Chen, M.L. Chen and J.H. Wang, J. Anal. At. Spectrom. 23, 412 (2008).

21. R.P. Monasterio, J. C. Altamirano, L.D. Martínez, and R.G. Wuillou, Talanta 77, 1290 (2009).

22. C.G. Rocha, A.I. Luiz, and S.R. Paulo, Mater. Res. 68, 25 (2005).

23. E. Kilinc, A. Dundar, S. Ozdemir, and V. Okumus, At. Spectrosc. 34, (78) 2013.

24. Y. Gu and X.S. Zhu, Microchim Acta 173, 433 (2011).

25. Z. Xuan, Y. Tang, X. Li, Y. Liu, and F. Luo, Biochem. Eng. J. 31, 160 (2006). 
26. S. Liang, X. Guo, N. Feng, and Q. Tian, J. Hazard. Mater. 170, 425 (2009).

27. X. Li, Y. Tang, Z. Xuan, Y. Liu, and F. Luo, Sep. Pur. Technol. 55, 69 (2007).

28. V. K. Gupta and A. Nayak, Chem. Eng. J. 180, 81 (2012).

29. N. Feng and X. Guo, Trans. Nonferrous Met. Soc. China, 22, 1224 (2012).

30. H. Hagendorfer and W. Goessler, Talanta 76, 656 (2008).

31. N. Feng, X. Guo, and S. Liang, J. Hazard. Mater. 164, 1286 (2009).

32. S. Liang, X. Guo, and Q. Tian, Desalination 275, 212 (2011).

33. P. Krystek and R. Ritsema, Int. J. Mass Spectrom. 265, 23 (2007).

34. D. Lu, Q. Cao, X. Li, X. Cao, F. Luo, and W. Shao, Hydrometallurgy 95, 145 (2009).

35. Y. Kalyan, Sadananda Das, A. K. Pandey, G. R. K. Naidu, P. K. Sharma, and A. V. R. Reddy, Anal. Methods 3, 2017 (2011).

36. S. Chen, L. Zhu, D. Lu, and X. Cheng, Microchim. Acta 169, 123 (2010). 